\title{
Modified K\&C model for cratering and scabbing of concrete slab under projectile impact
}

DOI:

10.1016/j.ijimpeng.2017.02.016

\section{Document Version}

Accepted author manuscript

Link to publication record in Manchester Research Explorer

\section{Citation for published version (APA):}

Kong, X. Z., Fang, Q., Li, Q. M., Wu, H., \& Crawford, J. (2017). Modified K\&C model for cratering and scabbing of concrete slab under projectile impact. International Journal of Impact Engineering, 108, 217-228.

https://doi.org/10.1016/j.jijimpeng.2017.02.016

\section{Published in:}

International Journal of Impact Engineering

\section{Citing this paper}

Please note that where the full-text provided on Manchester Research Explorer is the Author Accepted Manuscript or Proof version this may differ from the final Published version. If citing, it is advised that you check and use the publisher's definitive version.

\section{General rights}

Copyright and moral rights for the publications made accessible in the Research Explorer are retained by the authors and/or other copyright owners and it is a condition of accessing publications that users recognise and abide by the legal requirements associated with these rights.

\section{Takedown policy}

If you believe that this document breaches copyright please refer to the University of Manchester's Takedown Procedures [http://man.ac.uk/04Y6Bo] or contact uml.scholarlycommunications@manchester.ac.uk providing relevant details, so we can investigate your claim.

\section{OPEN ACCESS}


$4 \quad{ }^{\text {a }}$ State Key Laboratory for Disaster Prevention and Mitigation of Explosion and Impact, PLA University of Science and

5 Technology, Nanjing 210007, China

$6{ }^{\mathrm{b}}$ School of Mechanical, Aerospace and Civil Engineering, Pariser Building, The University of Manchester, Sackville

7 Street, Manchester M13 9PL, UK

$8{ }^{\mathrm{c}}$ State Key Laboratory of Explosion Science and Technology, Beijing Institute of Technology, Beijing 100081, China

$9{ }^{\mathrm{d}}$ Karagozian \& Case, 700 N. Brand Blvd., Suite 700, Glendale, CA 91203, U.S.A.

10 *Corresponding authors: Qin Fang: fangqinjs@139.com; Q.M. Li: Qingming.Li@manchester.ac.uk

\section{Abstract}

The K\&C material model, which was originally developed for the structural response

14 subjected to blast loadings, is modified to improve its numerical prediction capability for cratering

15 and scabbing phenomena in concrete slabs subjected to projectile impact. Four modifications are

16 made for the parameters of the strength surfaces, the dynamic increase factor for tension, the

17 relationship between yield scale factor and damage function, and the tensile damage accumulation.

18 Single element tests of the unconfined uniaxial compression, triaxial compression, dynamic

19 uniaxial tension as well as the biaxial and triaxial tensions are used to demonstrate the improved

20 performances of the modified $\mathrm{K} \& \mathrm{C}$ model. The modified concrete strength model is implemented

21 into the finite element code LS-DYNA through user-defined material model. The improved

22 predictions for cratering and scabbing phenomena under projectile impact using the modified $\mathrm{K} \& \mathrm{C}$

23 model are demonstrated by comparisons with the perforation tests and the corresponding 
24 simulation results from the original $\mathrm{K} \& \mathrm{C}$ model. Furthermore, sensitivity analyses of three

25 parameters that control the dynamic tensile behavior of the modified $\mathrm{K} \& \mathrm{C}$ model are carried out

26 to understand the influence of each individual parameter on the cratering and scabbing

27 phenomena.

28 Keywords: Concrete; Cratering; Scabbing; Modified K\&C model; Penetration

\section{Introduction}

When a concrete slab is subjected to projectile impact, cratering and scabbing phenomena

31 are frequently observed on its impact and distal surfaces, respectively [1-2]. Cratering involves in

32 the compressive stress wave propagation in the target, the reflected tensile stress wave on the

33 impact surface of the slab and the associated material failure [3]. Scabbing is caused by the

34 reflected tensile stress wave on the distal free surface. Numerical analyses of cratering and

35 scabbing in concrete slabs subjected to projectile impact [3-8] have showed that the tensile

36 strength, strain softening, fracture energy, and strain-rate effect on the tensile strength in a

37 concrete model can greatly influence the accurate modeling of cratering and scabbing

38 phenomena.

39 Tu and $\mathrm{Lu}$ [9] reviewed and evaluated several popular concrete models in commercial

40 hydrocodes, in which the Holmquist-Johnson-Cook concrete model (HJC model) has been widely

41 accepted for penetration studies because HJC model is valid mainly under the stress states

42 dominated by compression [10] which happens in the penetration process. For the stress states

43 dominated by tension, The HJC model uses the elastic, perfectly plastic constitutive equation,

44 which is independent of fracture energy. Further modifications of the HJC model focused mainly

45 on the compressive behavior [11] and the strain-rate effect [11-12]. Therefore, the HJC model and 
46 above-mentioned modified HJC models are not suitable for the tension-dominated phenomena,

47 e.g. cratering and scabbing. Huang et al. [4] employed a modified Taylor-Chen-Kuszmaul (TCK)

48 continuum damage model together with an erosion technique to simulate cratering and scabbing

49 of concrete slabs. The compressive behavior of the original TCK model [13] was replaced by the

50 damaged Mohr-Coulomb yield surface [4] because the original one is governed by von-Mises

51 yield surface, which is too simple to describe the concrete compressive behavior under high

52 pressure. The modified TCK model [4] showed reasonable predictions of cratering and scabbing

53 phenomena although the residual velocity was not well predicted, which was attributed to the

54 inaccuracy of the damaged Mohr-Coulomb yield surface in compression. In order to resolve this

55 issue, Liu et al. [5] employed the HJC and the TCK models to describe the dynamic compression

56 and tension, respectively. The calculated residual velocity was improved in comparison with the

57 predictions by Huang et al. [4]. However, the failure surface of the concrete material model by

58 Liu et al. [5] is discontinuous due to the separate treatments of the compressive behavior and

59 tensile behavior. Wang et al. [3] also presented a modified TCK model for numerical studies on

60 cratering and scabbing, in which the compressive damage was introduced. The common feature

61 of these studies is to apply the TCK model to describe the dynamic tensile behavior of concrete,

62 while the von-Mises compressive yield surface in the original TCK model was replaced by the

63 more suitable compressive yield surfaces (e.g. the Mohr-Coulomb or the HJC yield surfaces).

64 Because the TCK tensile model [13] considers the effects of strain-softening, strain-rate and

65 fracture energy under tensile loading, it is capable of predicting the brittle failure of concrete.

66 However, the TCK tensile model has nine differential equations to be integrated in each time step

67 in the implementation algorithm, which reduces the computational efficiency and may cause 
68 numerical instability. Besides, some parameters in the TCK tensile model, such as the volumetric

69 strain-rate experienced by concrete at fracture, are practically difficult to determine. Recently,

70 Kong et al. [8] presented several improvements to the HJC model, including the modified yield

71 surface, the introduction of tensile damage, the introduction of Lode-angle dependency and the

72 modified strain-rate effect, for the numerical simulations of cratering and scabbing phenomena.

73 Although the predictions have reasonably good agreements with corresponding experimental

74 results, there are still some shortcomings of the model, i.e., (i) strain hardening was not considered;

75 (ii) strain softening is only dependent on the cutoff of fracture strain (named EFMIN in [10]) that is

76 usually difficult to determine.

In order to improve the numerical predictions of cratering and scabbing phenomena in concrete, Leppänen [6] modified the RHT model [14] with a bi-linear tensile softening model based on fracture energy and strain-rate effect in tension. Tu and $\mathrm{Lu}$ [7] further made several enhancements to the modified RHT model by Leppänen [6], including the inclusion of the third

81 stress invariant in residual strength surface, and the improved tensile-to-compressive meridian ratio. Both Leppänen [6] and $\mathrm{Tu}$ and $\mathrm{Lu} \mathrm{[7]} \mathrm{assumed} \mathrm{that} \mathrm{the} \mathrm{fracture} \mathrm{energy} \mathrm{is} \mathrm{a} \mathrm{constant} \mathrm{and} \mathrm{the}$

83 fracture strain decreases with the increase of strain-rate in tension. This assumption is

84 inconsistent with recent experiments on tensile strength and fracture energy from instrumented

85 spalling tests [15-16], which suggested that the fracture strain at high strain-rate is a constant and 86 the fracture energy increases with the increase of strain-rate in tension. was originally developed to analyze structural response subjected to blast loadings, which has 
90 dynamic loads. However, this model still has some disadvantages, i.e., (i) In the version of

91 Release III, the automatic generations of parameters are provided and widely adopted by users.

92 These parameters, such as the parameters for the strength surfaces, are useful for relatively low

93 pressure, but may be inappropriate for very high pressure; (ii) For dynamic tensile behavior, both

94 the fracture strain and the fracture energy increase with the increase of the strain-rate in tension.

95 The increase of fracture strain with the increase of strain-rate is inconsistent with the

96 experimental observations [15-16], as discussed above; (iii) Tensile failure criterion is not

97 available, which plays an important role for the simulations of tensile-dominated failure

98 phenomena.

99 The present paper proposes a modified $\mathrm{K} \& \mathrm{C}$ model to improve its capability to predict

100 tensile failure in concrete (e.g. cratering and scabbing). After a brief description of the original

$101 \mathrm{~K} \& \mathrm{C}$ concrete material model, modifications for the strength surfaces parameters, the dynamic

102 increase factor for tension, the relationship between yield scale factor and damage function, and

103 the tensile damage accumulation will be presented in Section 2. The improved performances of

104 the modified K\&C model are demonstrated by single element numerical tests. Simulation results

105 and parametric analyses of concrete slabs subjected to projectile impact are presented in Sections

1063 and 4, respectively, which is followed by conclusive remarks in Section 5.

1072 Modified K\&C model

108 The original $\mathrm{K} \& \mathrm{C}$ model is introduced briefly before the modified $\mathrm{K} \& \mathrm{C}$ model is presented

109 where the improved performances due to the modifications are demonstrated by the single finite

110 element numerical tests. All parameters are obtained using the automatic generation method

111 offered by the original $\mathrm{K} \& \mathrm{C}$ model [18] unless stated otherwise. 


\subsection{The K\&C model in LS-DYNA}

113 Three independent strength surfaces of compressive meridians, namely, the initial yield

114 strength surface $\Delta \sigma_{y}$, the maximum strength surface $\Delta \sigma_{m}$ and the residual strength surface

$115 \Delta \sigma_{r}$ were used in the $\mathrm{K} \& \mathrm{C}$ model [17], i.e.,

116

117

118

$$
\begin{gathered}
\Delta \sigma_{y}=\left\{\begin{array}{l}
a_{0 y}+p /\left(a_{1 y}+a_{2 y} p\right), p \geq f_{y c} / 3 \\
1.35 T+3 p\left(1-1.35 T / f_{y c}\right), 0 \leq p \leq f_{y c} / 3 \\
1.35(p+T), p \leq 0
\end{array}\right. \\
\Delta \sigma_{m}=\left\{\begin{array}{l}
a_{0}+p /\left(a_{1}+a_{2} p\right), p \geq f_{c} / 3 \\
(1.5 / \psi)(p+T),\left\{0 \leq p \leq f_{c} / 3\right\} \text { or }\left\{\lambda \leq \lambda_{m} \text { and }-T \leq p \leq f_{c} / 3\right\} \\
3(p / \eta+T), p \leq 0 \text { and } \lambda>\lambda_{m}
\end{array}\right.
\end{gathered}
$$

119 where $a_{i}, a_{i y}$ and $a_{i f}(i=0,1,2)$ are constants determined from a suitable set of triaxial

120 compression test data. $f_{y c}=0.45 f_{c}, f_{c}$ and $T$ are the initial yield strength, unconfined uniaxial

121 compressive strength and tensile strength, respectively. $p$ is the hydrostatic pressure, and $\psi$

122 denotes the tensile-to-compressive meridian ratio, which is determined by a linear interpolation of

123 the discrete points described by [17],

124

$$
\psi(p)= \begin{cases}\frac{1}{2} & p \leq 0 \\ \frac{1}{2}+\frac{3 T}{2 f_{c}} & p=\frac{f_{c}}{3} \\ \frac{\alpha f_{c}}{2 \alpha f_{c}} & p=\frac{2 \alpha f_{c}}{3}, \alpha \approx 1.15 \\ a_{0}+\frac{2 a_{1}+2 \alpha a_{2} f_{c}}{0.753} & p=3 f_{c} \\ 1 & p \geq 8.45 f_{c}\end{cases}
$$

As observed from Eqs. (1-2), the initial yield strength surface and the maximum strength 
$127\left(p \geq f_{c} / 3\right)$ is defined by available data of the unconfined uniaxial compression (UUC) test and

128 the triaxial compression (TXC) test. If there is no available test data for the second segment

$129\left(\left\{0 \leq p \leq f_{c} / 3\right\}\right.$ or $\left\{\lambda \leq \lambda_{m}\right.$ and $\left.\left.-T \leq p \leq f_{c} / 3\right\}\right)$ because the pressure is lower than the pressure

130 domain of the UUC test, the second segment is obtained by dividing the tensile meridian with the

131 tensile-to-compressive meridian ratio $\psi(p)$. For the third segment $\left(p \leq 0\right.$ and $\left.\lambda>\lambda_{m}\right)$,

132 strain-softening happens. Therefore, the pressure cutoff $(-T \eta)$ is applied, and the maximum

133 strength surface is a linear interpolation between the zero-pressure point at the second segment

$134\left(p=0, \Delta \sigma_{m}=3 T\right)$ and the pressure cutoff point $\left(p=-T \eta, \Delta \sigma_{m}=0\right)$.

135 For the initial yield strength surface, the first segment $\left(p \geq f_{y c} / 3\right)$ is defined by available

136 TXC data, which suggest that $\Delta \sigma_{y}=0.45 \Delta \sigma_{m}$ [17]. If there is no available test data for the

137 second segment $\left(0 \leq p \leq f_{y c} / 3\right)$, the second segment is obtained as a linear interpolation between

138 the yield point $\left(p=f_{y c} / 3, \Delta \sigma_{m}=f_{y c}\right)$ and the point proportional (45\%) to the maximum strength

139 surface at zero pressure $\left(p=0, \Delta \sigma_{m}=1.35 T\right)$. For the third segment $(p \leq 0)$, the peak pressure

140 can be $-T$ since the strain-hardening undergoes before yielding, and the initial yield strength

141 surface is a linear interpolation between the triaxial tension point $\left(p=-T, \Delta \sigma_{m}=0\right)$ and the $45 \%$ of

142 the maximum surface at zero pressure $\left(p=0, \Delta \sigma_{m}=1.35 T\right)$. The definition of the residual strength

143 surface is rather simple as shown in Eq. (3), which can be obtained by fitting TXC data since

144 residual strength can be identified from stress-strain curves of TXC data. It is noted that $a_{0 f}$

145 should be zero since the residual strength should vanish for the UUC test.

146 Advantages of these strength surfaces, especially at $p<f_{c} / 3$, have been illustrated in [9],

147 which will not be repeated here. A typical view of the strength surfaces for $f_{c}=50 \mathrm{MPa}$ is shown in

148 Fig. 1, where the parameters $a_{i}, a_{i y}$ and $a_{i f}$ are determined by the automatic generation 
of the plastic strain increment in a time step. The damage constants $b_{1}$ and $b_{2}$ usually have different values for compression and tension with considering different damage evolutions of concrete. The

161 yield scale factor $\eta$ follows a general trend, i.e., it varies from zero to unity when the current failure surface changes from the initial yield strength surface to the maximum strength surface

The current failure surface was determined as follows,

$$
\Delta \sigma=\sqrt{3 J_{2}}=\left\{\begin{array}{l}
r^{\prime}\left[\eta\left(\Delta \sigma_{m}-\Delta \sigma_{y}\right)+\Delta \sigma_{y}\right], \text { strain hardening } \\
r^{\prime}\left[\eta\left(\Delta \sigma_{m}-\Delta \sigma_{r}\right)+\Delta \sigma_{r}\right], \text { strain softening }
\end{array}\right.
$$

where $J_{2}$ is the second deviatoric stress invariant. $r^{\prime}$ is the ratio of the current meridian to the compressive meridian. $\eta$ is the yield scale factor related to the damage function $\lambda$, which is determined by,

$$
\lambda=\sum\left\{\begin{array}{l}
\Delta \bar{\varepsilon}_{p} /(1+p / T)^{b 1}, p>0 \\
\Delta \bar{\varepsilon}_{p} /(1+p / T)^{b 2}, p \leq 0
\end{array}\right.
$$

where $\Delta \bar{\varepsilon}_{p}=\sqrt{(2 / 3) \Delta \varepsilon_{i j}^{p} \Delta \varepsilon_{i j}^{p}}$ is the effective plastic strain increment with $\Delta \varepsilon_{i j}^{p}$ being the tensor corresponding to the strain hardening stage, and it varies from unity to zero when the current failure

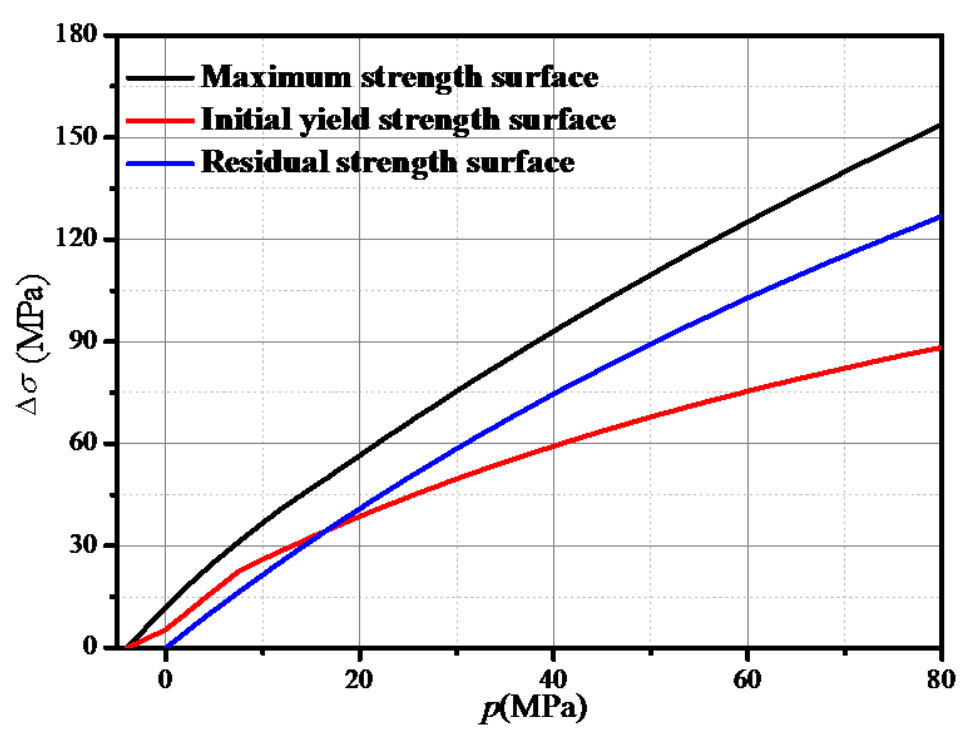

Fig. 1 Three independent strength surfaces $\left(f_{c}=50 \mathrm{MPa}\right)$ 
164 surface changes from the maximum strength surface to the residual strength surface corresponding

165 to the strain softening stage. It should be noted that no accumulative plastic strain occurs when the

166 stress path is close to the triaxial tensile path where stress deviators approach zero. Consequently,

167 both the damage function $\lambda$ and the yield scale factor $\eta$ remain zero, which cannot represent the

168 actual situation. To overcome this problem, a volumetric damage scalar related to pressure was

169 introduced [17], which will not be repeated here.

170 To account for the strain-rate effect, the current failure surface and the damage function

$171 \lambda$ were modified as follows,

$$
\Delta \sigma=r_{f} \Delta \sigma\left(p / r_{f}\right), \lambda=\lambda\left(p / r_{f}\right) / r_{f}
$$

173 where $r_{f}$ is the dynamic increase factor (DIF), which was defined separately for compression and

174 tension, since experimental data showed that DIF for tension is much higher than that for

175 compression. The determination of DIF will be discussed further in Section 2.3.

176 For the complete description of concrete behavior, a proper equation of state (EOS) is

177 needed to relate pressure to volumetric strain. K\&C model uses the tabulated compaction EOS

178 (EOS \#8) in LS-DYNA, which describes the current pressure $p$ as a function of the volumetric

179 strain $\mu$

$$
p=C(\mu)+\gamma_{0} \theta(\mu) E_{0}
$$

181 where $E_{0}$ is the internal energy per initial volume, and $\gamma_{0}$ is the ratio of specific heat. $C(\mu)$

182 and $\theta(\mu)$ are the tabulated pressure evaluated along a 0-degree-Kelvin isotherm and tabulated

183 temperature-related parameter as functions of the volumetric strain, respectively. In the loading

184 stage, pressure is determined by extrapolating the tabulated function given in Eq. (8). As shown in

185 Fig. 2, unloading occurs along the unloading bulk modulus to the pressure cutoff. Reloading 
186 follows the unloading path to the point where unloading begins, and continues on the loading path.

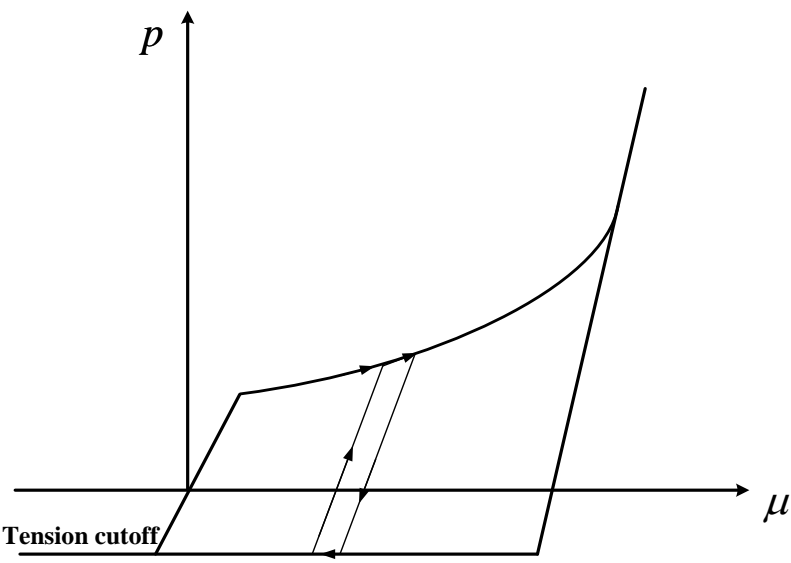

Fig. 2 Equation of state

\subsection{Modified strength surfaces parameters}

In the original $\mathrm{K} \& \mathrm{C}$ model, the strength surfaces parameters were obtained from the triaxial

191 compression data of 45.4MPa concrete and expressed as functions of concrete compressive 192 strength [18], i.e.,

$$
a_{0}=0.2956 f_{c} ; a_{1}=0.4463 ; a_{2}=0.0808 / f_{c}
$$

$$
a_{0 y}=0.2232 f_{c} ; a_{1 y}=0.625 ; a_{2 y}=0.2575 / f_{c}
$$

Eq. (9) is suitable for relatively low pressure. However, for the projectile impact problem

197 concerned here, the pressure around the projectile-target interface can reach a magnitude in the

198 order of GPa. Consequently, the strength surfaces parameters should be re-determined. A large

199 amount of triaxial compression data are shown in Fig. 3. It can be clearly observed that Eq. (9a)

200 has good agreement with the experimental data when $p / f_{c}<3$, beyond which the deviation 201 increases with the increase of pressure. A new set of the maximum strength surface parameters is 202 proposed from curve-fitting the data shown in Fig. 3 as follows, 


$$
a_{0}=0.4426 f_{c} ; a_{1}=0.5698 ; a_{2}=0.02516 / f_{c}
$$

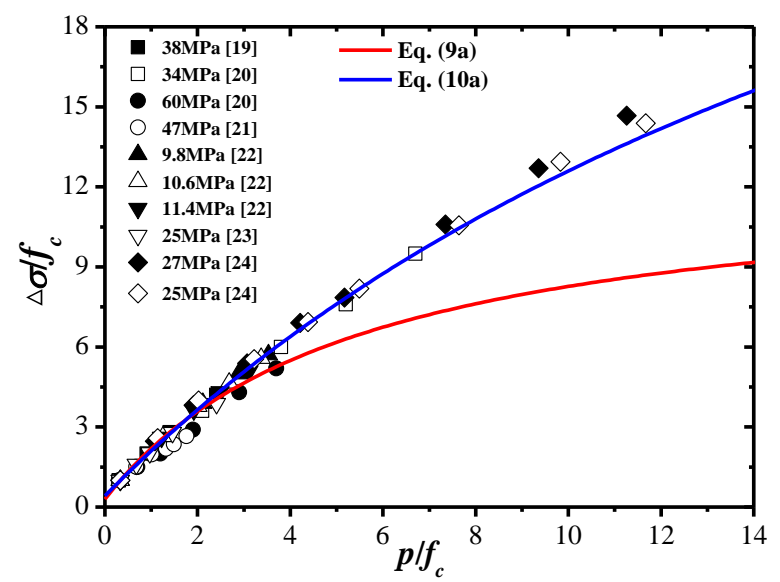

Fig. 3 Triaxial compression data as well as predictions from Eq. (9a) and Eq. (10a)

It should be pointed out that Eq. (10a) deviates from experimental data for high pressure

enough for $p / f_{c}>12$. However, the generality of above curve-fitting approach is not affected, and the experimental data for high pressure become available.

By assuming $\Delta \sigma_{y}=0.45 \Delta \sigma_{m}$, the initial yield surface parameters can be obtained

212 following the same way proposed in [17],

$$
a_{0 y}=0.2797 f_{c} ; a_{1 y}=0.8989 ; a_{2 y}=0.0685 / f_{c}
$$

For the determination of the residual strength surface parameters, the residual strength from

215 triaxial compression experiments is needed, which, however, is difficult to find in the relevant

216 literatures. Noting that the residual strength surface should be parallel with the maximum strength

217 surface for high pressure, the residual strength surface parameters are proposed as follows,

$$
a_{0 f}=0 ; a_{1 f}=a_{1} ; a_{2 f}=a_{2}
$$


220 concern is the accuracy of the automatically generated EOS parameters discussed below. For the

221 EOS of concrete material, the available experimental data is limited. The isotropic compression

222 data from Hanchak et al. [1] for 48MPa concrete as well as the full-scale explosive detonation and

223 flyer-plate-impact data from Gebbeken et al. [25] for 51.2MPa concrete are plotted on Fig. 4. Using

224 the automatically generated parameters of the original $\mathrm{K} \& \mathrm{C}$ model gives a satisfactory agreement

225 with the experimental data. Therefore, the automatically generated EOS parameters are adopted in

226 the present study.

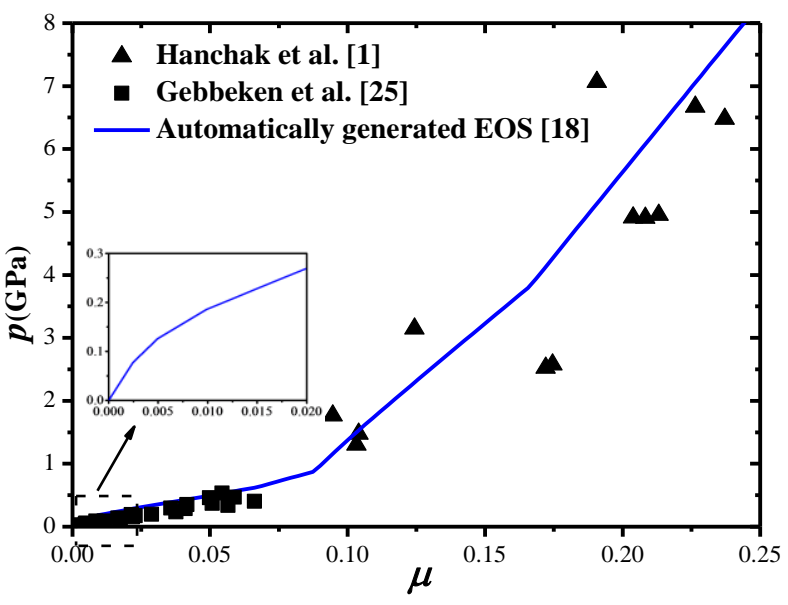

Fig. 4 Pressure-volumetric strain test data and predicted EOS using automatically generated

parameters

\subsection{Modified DIFt}

A previous study [8] showed that the dynamic increase factor for tension (DIFt) has a strong

232 influence on the cratering and scabbing damage of concrete slabs subjected to projectile impact.

233 Therefore, an accurate relationship between DIFt and strain-rate is essential. Numerical analysis

234 [26] concluded that DIFt observed in the dynamic tensile tests is a genuine material effect,

235 consequently, DIFt obtained from curve-fitting experimental data can be applied to material 236 model directly. 
So far, there are many suggested relationships between DIFt and strain-rate in the literatures

238 [27-30], which are plotted on Fig. 5 along with the experimentally-obtained DIFt. It is found that,

239 the CEB-FIB recommended DIFt, which was widely used in previous studies, greatly

240 underestimates the test data. The empirical formula suggested by $\mathrm{Xu}$ and Wen [30] shows good

241 agreement with the test data, and therefore, is used in the present study, i.e.,

$$
\mathrm{DIFt}=\left\{\left[\tanh \left(\left(\log \left(\dot{\varepsilon} / \dot{\varepsilon}_{0}\right)-W_{x}\right) S\right)\right]\left(F_{m} / W_{y}-1\right)+1\right\} W_{y}
$$

243 where $\dot{\varepsilon}_{0}=1 \mathrm{~s}^{-1}$ is the reference strain rate, $F_{m}=10, W_{x}=1.6, S=0.8$ and $W_{y}=5.5$ are the fitting 244 constants.

245 This paper adopts the recommended dynamic increase factor for compression (DIFc) in 246 K\&C model (i.e., CEB model in compression [27]) for consistency. However, it has been 247 demonstrate that DIFc obtained from the dynamic compressive tests includes the "structural effect" 248 induced by the lateral confinement effect especially when the strain-rate is greater than a critical 249 transition strain-rate between $10^{1}$ and $10^{2} \mathrm{~s}^{-1}$ for concrete [31-33]. The lateral confinement effect 250 may significantly overestimate DIFc in a SHPB test for high strain-rates that happen frequently in 251 impact and blast loaded concrete structures. The latest version of $\mathrm{K} \& \mathrm{C}$ model introduced a cutoff 252 value of 2.94 for DIFc, which can avoid the overestimations of DIFc at high strain-rates, and it will 253 be used in the present study. 


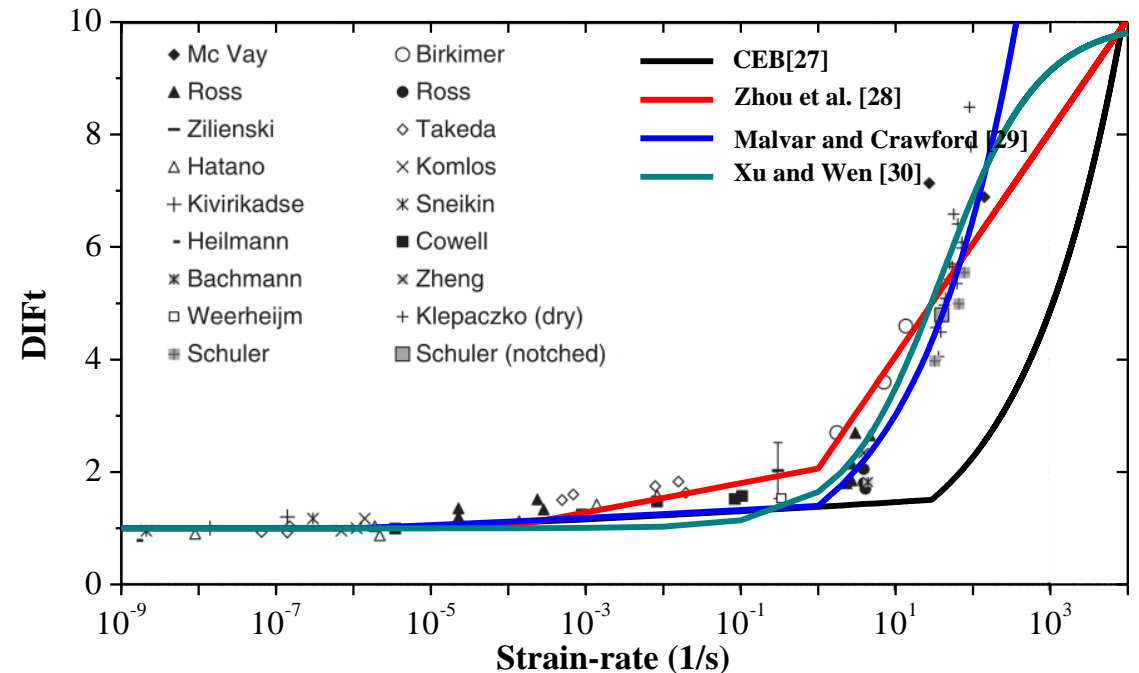

Fig. 5 Experimental DIFt and suggested relations (test data reprinted from [15])

\subsection{Modified relationship between $\eta$ and $\lambda$}

In the implementation of the original $\mathrm{K} \& \mathrm{C}$ model, the relationship between $\eta$ and $\lambda$ is taken

258 as a piece-wise linear curve. If the automatically generated method is not adopted, 13 pairs of

$259\left(\lambda_{i}, \eta_{i}\right)$ must be carefully defined, which is inconvenient for practical application.

A new relationship between $\eta$ and $\lambda$ is proposed as follows,

$$
\eta(\lambda)=\left\{\begin{array}{l}
\alpha \lambda / \lambda_{m}+(3-2 \alpha)\left(\lambda / \lambda_{m}\right)^{2}+(\alpha-2)\left(\lambda / \lambda_{m}\right)^{3}, \lambda \leq \lambda_{m}, \text { strain hardening } \\
\frac{\lambda / \lambda_{m}}{\alpha_{c}\left(\lambda / \lambda_{m}-1\right)^{\alpha_{d}}+\lambda / \lambda_{m}}, \lambda>\lambda_{m}, \text { strain softening }
\end{array}\right.
$$

where $\alpha, \alpha_{c}$ and $\alpha_{d}$ are the constants govern the strain hardening and softening stages,

respectively. $\lambda_{m}$ is the corresponding value of $\lambda$ when $\eta=1 . \alpha, \alpha_{c}, \alpha_{d}$ and $\lambda_{m}$ can be obtained by trial-and-error method until the predicted uniaxial stress-strain curve agrees well with the recommended uniaxial stress-strain relations, such as those in [27] and [34]. $\alpha=3, \alpha_{c}=0.29$, $\alpha_{d}=1.86$ and $\lambda_{m}=8.7 \mathrm{e}-5$ are suggested based on a large amount of trial calculations.

Attard and Setunge [34] developed an empirical analytical model for the full stress-strain 
269 broad range of concrete strengths between $20 \mathrm{MPa}$ and $130 \mathrm{MPa}$. The stress-strain curves for

$27050 \mathrm{MPa}$ concrete under different confinement pressure $\left(P_{c o n}\right)$ obtained from the modified $\mathrm{K} \& \mathrm{C}$

271 model described in this section and the original K\&C model are compared with the empirical

272 formula suggested by Attard and Setunge [34], as shown in Fig. 6. It can be observed that the

273 modified model shows good agreement with the empirical formula, while the original K\&C model

274 is stiffer in the loading stage and has larger softening gradient when compared with the empirical

275 formula. In addition, the original $\mathrm{K} \& \mathrm{C}$ model overestimates the peak stress, while the modified

276 model has good agreement with the empirical peak stress due to the use of the new strength

277 surfaces parameters given in Eq. (10).

278

279 Fig. 6 Comparisons of compressive stress-strain curves of 50MPa concrete developed by Attard

280 and Setunge [34] with those by modified and original K\&C models obtained from single element

281 test

\subsection{Modified tensile damage accumulation}

A typical load-displacement curve for uniaxial tension is shown in Fig. 7(a) where $\delta$ is the

284 deformation of the fracture zone and $F$ is the tensile force. The subscripts $m$ and frac denote the

285 corresponding quantities at the maximum strength and fracture, respectively. It should be pointed 
286 out that $\delta$ cannot be represented by the total displacement in a uniaxial tension test as the

287 fracture occurs in a localized zone. A previous study [16] showed that $\delta$ is in the order of 0.1

$288 \mathrm{~mm}$.

289 In order to determine the relation between stress and strain that is necessary for material 290 model, a relation between the deformation $\delta$ and the tensile strain $\varepsilon$ must be assumed. 291 Following the assumption made in [16], in which $\varepsilon$ is defined as $\delta / l_{\text {frac }}$, the corresponding 292 stress-strain curve can be obtained, as shown in Fig. 7(b), where $l_{\text {frac }}$ denotes the length of the 293 fracture zone (crack width) [16] over which the microcracks are assumed to be uniformly spread.

294 Extensive static and dynamic tensile tests have been conducted previously, but there is little 295 quantitative information about the size of the fracture zone [16]. Based on the recommendation of 296 Bazant for static loading, the size of the fracture zone is typically 1-6 times of the maximum 297 aggregate size [17].

298 Since the static fracture energy $G_{f}$ required to fail the concrete is dissipated within $l_{f r a c}$, the 299 specific strain energy in the entire cracking process should meet the following energy 300 conservation condition [16], 


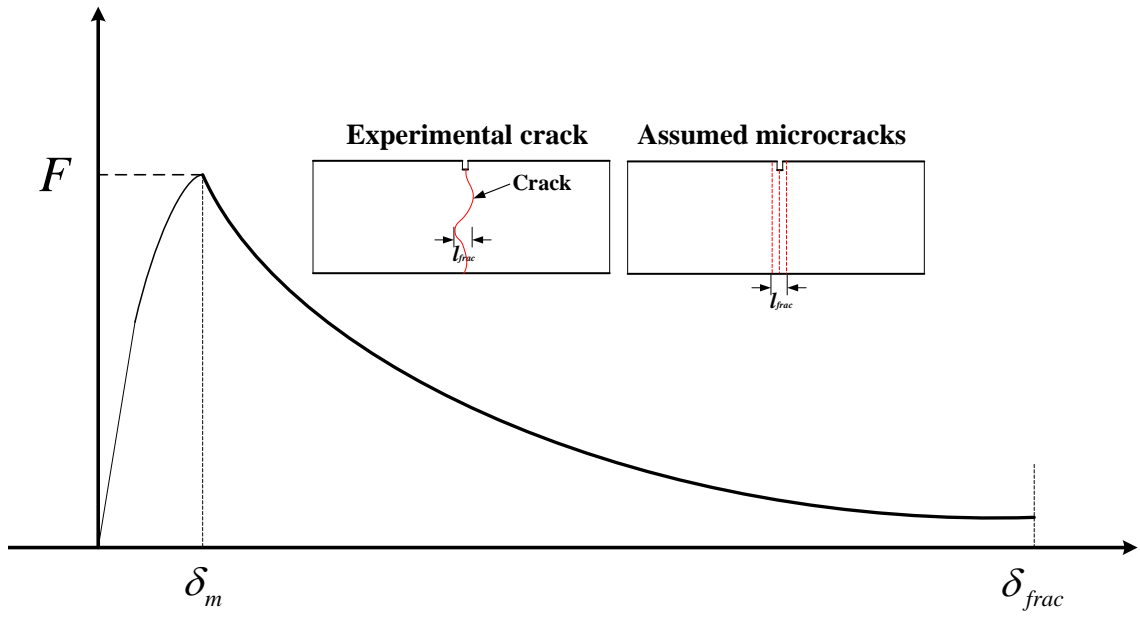

(a)

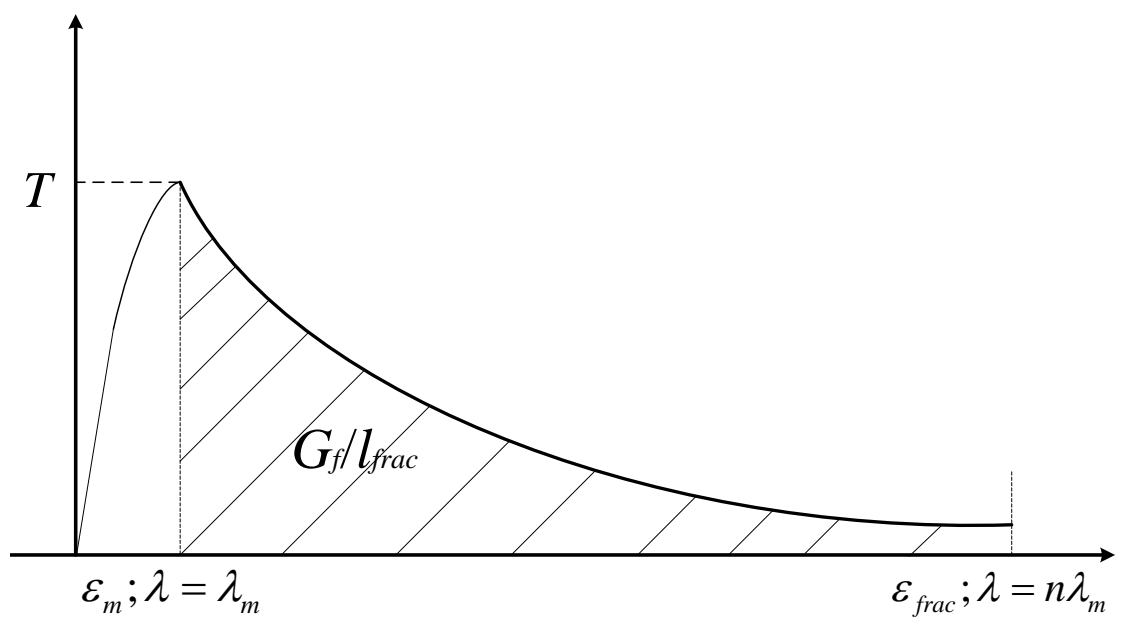

(b)

306 Fig. 7 Typical load-displacement and stress-strain curves for uniaxial tension: (a)

307 load-displacement curve; (b) stress-strain curve

In FE-simulations, $l_{\text {frac }}$ is always related to the characteristic length of the element $h_{c}$, which

309 can be approximated by the cube root of the volume of an element in a 3-D analysis [7].

310 Previously, $l_{\text {frac }}=h_{c}$ was always used $[7,8]$ based on the assumption that the tensile fracture occurs

311 in one element, as shown in Fig. 8(a). However, for the accurate simulations of cratering and

312 scabbing phenomena, $h_{c}$ is usually needed to be smaller than $l_{\text {frac }}$, which means that the fracture

313 occurs in several elements, as shown in Fig. 8(b). Consequently, the element of size $h_{c}$ will 
314 dissipate fracture energy of $\left(h_{c} / l_{\text {frac }}\right) G_{f}$, since $\left(l_{\text {frac }} / h_{c}\right)$ of them are needed to fill the fracture zone

315 and develop the fracture energy of $G_{f}$.

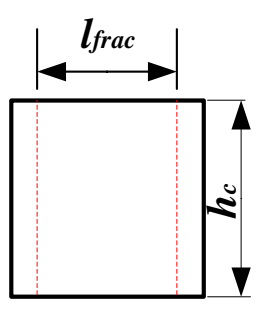

(a)

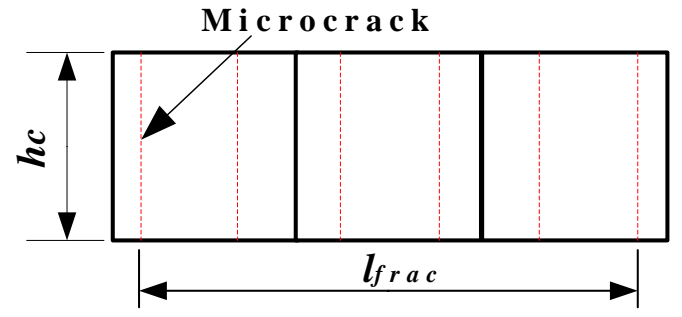

(b)

318 Fig. 8 Schematic diagram of the relationship between $l_{\text {frac }}$ and $h_{c}$, tensile fracture occurs in (a) one

319 element; (b) several elements

In the original $\mathrm{K} \& \mathrm{C}$ model, if not provided, $l_{f r a c}$ can be taken as the element size $h_{c}$, but no

321 less than three times of the maximum aggregate size of concrete. When $l_{\text {frac }}=10 \mathrm{~cm}$ and $G_{f}$ is

322 around 100N/m, Eq. (13) is satisfied. For other lengths of the fracture zone, in order to satisfy Eq.

323 (13) and maintain the static fracture energy around $100 \mathrm{~N} / \mathrm{m}$ at the same time, a relative element

324 size parameter $r$ size $=l_{\text {frac }} /(10 \mathrm{~cm})$ was introduced to obtain the new damage function values for the

325 strain softening stage as follows,

$$
\lambda_{i}^{\prime}=\lambda_{m}+\left(\lambda_{i}-\lambda_{m}\right) / r s i z e
$$

327 where the subscript $i$ ranges from 6 to 13, corresponding to the strain softening stage. Then the

328 relationship between $\eta$ and $\lambda$ for strain softening is taken as a piece-wise linear curve using new

329 pairs of $\left(\lambda_{i}^{\prime}, \eta_{i}\right)$ shown in Eq. (14).

330 There are several weaknesses of the $\mathrm{K} \& \mathrm{C}$ tensile damage model, as discussed below,

331 (1) For the static fracture energy far from $100 \mathrm{~N} / \mathrm{m}, b_{2}$ must be re-determined by adjusting its

332 value until Eq. (13) is satisfied, which is time-consuming. 
(2) Since the relationship between $\eta$ and $\lambda$ controls both the compressive and tensile

334 behaviors of concrete material, as discussed in Section 2.1, the above treatment for ensuring the

335 static fracture energy affects not only the tensile strain softening stage, but also the compressive

336 strain softening stage. When the length of fracture zone is relatively small, the compressive strain

337 softening will be not obvious, making concrete material relatively "hard", which may be

338 unrealistic for the FE-simulation of penetration where the compressive strain softening plays an

339 important role in the penetration resistance.

340 (3) As will be shown in Fig. 9, for the original K\&C model, both the predicted fracture strain

341 and the fracture energy increase with the increase of the strain-rate. The increase of fracture strain

342 with the increase of strain-rate is inconsistent with recent experimental observation [15-16] that

343 the fracture strain at high strain-rate is almost a constant.

344 In order to address the three issues above, the tensile damage accumulation is modified as

345 follows,

$$
\lambda=\sum \begin{cases}\frac{\Delta \bar{\varepsilon}_{p}}{r_{f}\left(1+p / r_{f} T\right)^{b_{2}}}, p<0 & \text { and } \quad \lambda<\lambda_{m} \\ \frac{\Delta \bar{\varepsilon}_{p}}{e l s}, \quad p<0 & \text { and } \quad \lambda \geq \lambda_{m}\end{cases}
$$

347 where els is a constant related to the length of fracture zone and the static fracture energy.

348 According to Eq. (15), the tensile damage accumulation for the strain hardening stage is the same

349 as that in the original $\mathrm{K} \& \mathrm{C}$ model while a modification is made for the strain softening stage.

350 Considering the elastic strain limit is relatively small, $\int_{\varepsilon_{m}}^{\varepsilon_{\text {frac }}} \sigma d \varepsilon \approx \int_{\varepsilon_{m}}^{\varepsilon_{\text {frac }}} \sigma d \varepsilon_{p}$ can be obtained. By

351 assuming that the tensile failure happens at $\lambda=n \lambda_{m}$, where the stress approaches zero, as shown in

352 Fig. 7(b), the left side of Eq. (13) can be replaced by, 


$$
\int_{\varepsilon_{m}}^{\varepsilon_{\text {frac }}} \sigma d \varepsilon \approx \int_{\varepsilon_{m}}^{\varepsilon_{\text {frac }}} \sigma d \varepsilon_{p}=\int_{\varepsilon_{m}}^{\varepsilon_{\text {frac }}} T \eta d \varepsilon_{p}
$$

354 where $\eta$ is given by Eq. (12b).

further transformed into,

$$
\int_{\varepsilon_{m}}^{\varepsilon_{\text {frac }}} T \eta d \varepsilon_{p}=\int_{\lambda_{m}}^{n \lambda_{m}} T \eta(e l s) d \lambda=T \times(e l s) \times \lambda_{m} \int_{1}^{n} \frac{x}{\alpha_{c}(x-1)^{\alpha_{d}}+x} d x
$$

where Eq. (12b) is applied. Based on Eqs. $(13,17)$, els can be expressed by

$$
e l s=\frac{G_{f}}{l_{\text {frac }} \times T \times \lambda_{m} \int_{1}^{n} \frac{x}{\alpha_{c}(x-1)^{\alpha_{d}}+x} d x}
$$

Consequently, the fracture strain can be determined according to Eq. (15) as

$$
\varepsilon_{\text {frac }}=n \lambda_{m} e l s
$$
18-19) directly in the proposed tensile damage model, which avoids the time-consuming parameter calibration in the original $\mathrm{K} \& \mathrm{C}$ model. It is observed that els is proportional to $G_{f}$ and

365 inversely proportional to $l_{\text {frac }}, T, \lambda_{m}$ and $\int_{1}^{n} x /\left[\alpha_{c}(x-1)^{\alpha_{d}}+x\right] d x$. Furthermore, els 366 decreases with the increase of $n$ as a hyperbolic way since $\int_{1}^{n} x /\left[\alpha_{c}(x-1)^{\alpha_{d}}+x\right] d x$ approaches to a constant when $n$ approaches to an infinite value. In addition, as shown in Eq. (15), the proposed tensile damage model does not affect the compressive strain softening stage, which may be more suitable than the original $\mathrm{K} \& \mathrm{C}$ model. In order to further gain insights into the modified tensile damage accumulation, dynamic tensile stress-strain curves for 50MPa concrete under different strain-rates are calculated. The static fracture energy is assumed to be $85 \mathrm{~N} / \mathrm{m}$ which is 
372 the same as the automatic generated one in the original $\mathrm{K} \& \mathrm{C}$ model. The length of fracture zone

373 is assumed to be equal to the side length of the cubic element (10mm). Using Eqs. (18-19), els

374 and $\varepsilon_{\text {frac }}$ are obtained as 1.15 and 0.01 , respectively. As will be discussed in Section 4.1, the

375 parameter $n$ has limited influence on the scabbing simulation results when it is larger than 100

376 where the tensile stress approaches zero. Consequently, it is set as 100 . The predicted stress-strain

377 curves at different strain-rates are shown in Fig. 9, where the results from the original K\&C

378 model are also presented for comparison purpose. It can be observed that, for the present model,

379 the fracture strain is a constant and the fracture energy increases with the increase of the

380 strain-rate, which is consistent with the experimental observations [15-16]. While for the original

$381 \mathrm{~K} \& \mathrm{C}$ model, both the fracture strain and the fracture energy increase with the increase of the

382 strain-rate, which may overestimate the fracture energy at high strain-rate.

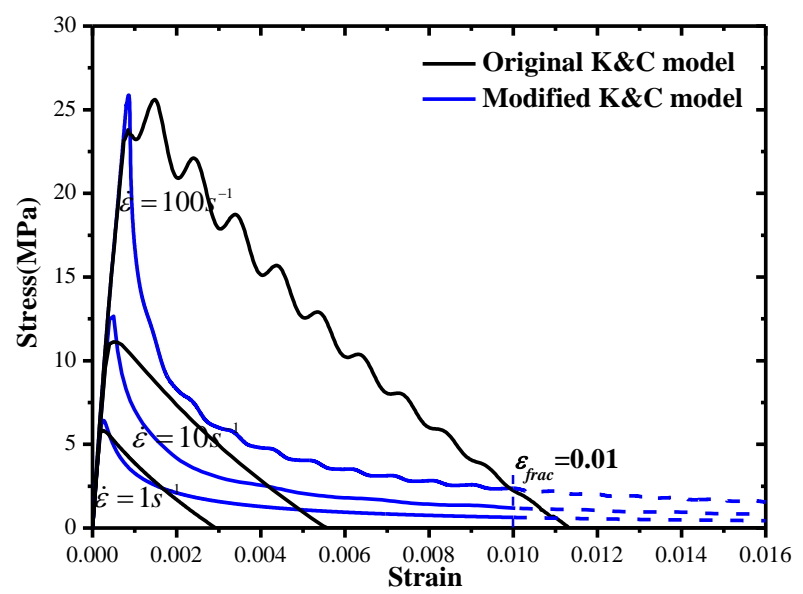

384 Fig.9 Comparisons of dynamic tensile stress-strain curves between modified and original K\&C 385 models obtained from single element test.

The predicted stress-strain curves for biaxial and triaxial tensions are also of interest and

387 shown in Fig. 10. For the biaxial tension, it is found that, the strain softening using the original

$388 \mathrm{~K} \& \mathrm{C}$ model is almost linear, which does not give a good prediction. For the triaxial tension, 
389 although the volumetric damage was considered in the original $\mathrm{K} \& \mathrm{C}$ model [17], the predicted

390 stress-strain relation is elastic, perfectly plastic, indicating that there may be an error during the

391 implementation of the volumetric damage into LS-DYNA. The modified model describes the

392 strain softening well for both biaxial and triaxial tensions.

393

394

395

396

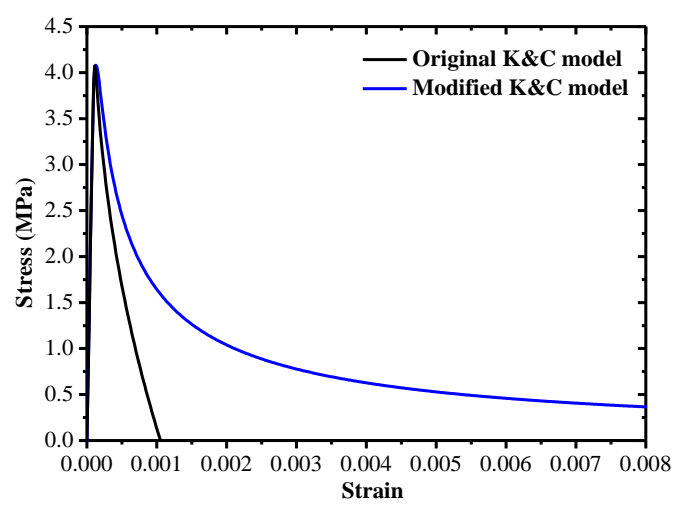

(a)

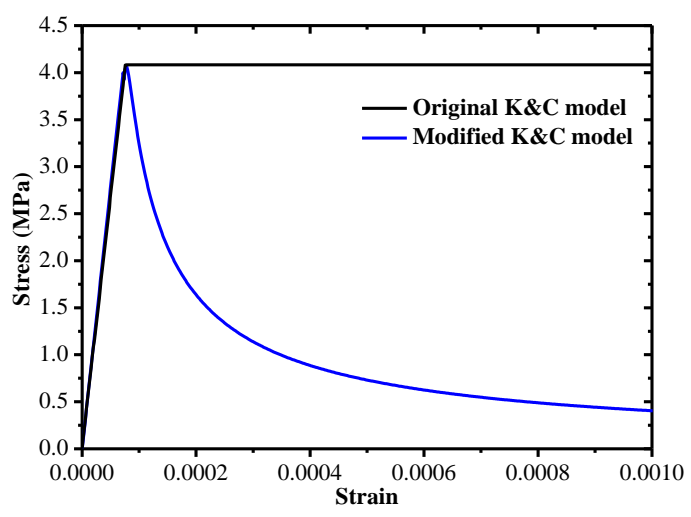

(b)

Fig.10 Stress-strain curves for biaxial and triaxial tensions of modified and original K\&C models obtained from single element tests: (a) biaxial tension; (b) triaxial tension

The original K\&C model has total 48 parameters, which can be generated automatically using the unconfined compressive strength if this function is opted. This is an attractive feature for engineering applications and case studies. It is worth pointing out that this attractive feature is also available in the modified $\mathrm{K} \& \mathrm{C}$ model, which has total 23 parameters that can all be calculated for a given $f_{c}$ according to the above-mentioned approaches.

\section{Numerical simulations of cratering and scabbing in concrete slabs subjected to projectile}

\section{impact}

The proposed modified concrete material model is implemented into the finite element code

LS-DYNA [35] through user-defined material model. In order to ensure that the modified model can predict cratering and scabbing phenomena as well as projectile residual velocity at the same

407 time, corresponding results from several experiments with varying projectile impact velocity and 
408 concrete slab thickness should be realistically reproduced. Projectile perforation experiments into

409 concrete slabs conducted by $\mathrm{Wu}$ et al. [2] are numerically simulated to validate the present

410 modified model, in which a newly proposed erosion criterion is used. Furthermore, the

411 corresponding simulation results of the original $\mathrm{K} \& \mathrm{C}$ model are also presented to show improved

412 performances of the modified K\&C model.

\section{$413 \quad 3.1$ New erosion criterion}

414 For the numerical simulations using the finite element approach, an erosion algorithm is

415 essential and should be carefully introduced to capture the physical crush (compressive failure)

416 and the fracture (tensile failure) of concrete material. When the specified variable of an element

417 used to represent the compressive or tensile failure reaches its critical value, the element is

418 deleted immediately. It is generally accepted that the compressive failure can be represented by

419 the effective plastic strain [4-5] or the maximum principal strain [6-7, 11-12]. For the tensile

420 failure, the criterion is still inconclusive. The tensile damage in the modified TCK model was

421 considered in previous studies [3-5] as the criterion for the tensile failure. However, the value of

422 tensile damage criterion was determined empirically as 0.5. Recently, $\mathrm{Xu}$ and $\mathrm{Lu}$ [36] as well as $\mathrm{Li}$

423 and Hao [37] proposed a tensile fracture strain criterion with an empirical critical value of 0.01

424 for the tensile failure of concrete material, which demonstrated good agreements with

425 experimental results. However, it was observed that the simulation results for scabbing are

426 sensitive to the critical tensile fracture strain [8], which affects its applications.

427 To resolve the empirical and sensitive issues in above tensile failure criteria, a new tensile

428 failure criterion is proposed as follows, 


$$
\Delta \lambda_{t}=\left\{\begin{array}{c}
0, p>0 \\
\Delta \bar{\varepsilon}_{p} /\left[r_{f}\left(1+p / r_{f} T\right)^{b_{2}}\right], p<0 \quad \text { and } \lambda<\lambda_{m} ; \lambda_{t}=\sum \Delta \lambda_{t} \\
\Delta \bar{\varepsilon}_{p} / e l s, p<0 \quad \text { and } \lambda \geq \lambda_{m}
\end{array}\right.
$$

430 where the prefix $\Delta$ refers to the increment of a variable during a time step. When $\lambda_{t}$ reaches $n \lambda_{m}$,

431 the tensile failure occurs, and the element should be deleted immediately. Although an empirical

432 constant $n$ is introduced in the present tensile failure criterion, it will be shown in Section 4.1 that

433 the influence of $n$ on the scabbing simulation results is small when it is greater than 100 because

434 the tensile stress approaches to zero when the strain is large, as shown in Fig. 9. The compressive

435 failure is still represented by the effective plastic strain $\bar{\varepsilon}_{p}$.

\section{$436 \quad 3.2$ Simulation results}

437 Recently, we conducted twenty five shots of reduce-scaled projectile perforation tests on five

438 configurations of monolithic and segmented RC panels with a layer of rear steel plate [2]. The

439 cratering and scabbing size, residual velocity and the projectile acceleration were carefully

440 recorded, which provide experimental data for the validation of the modified $\mathrm{K} \& \mathrm{C}$ model.

441 In our experiments, the projectiles were shot into cuboid 41MPa reinforced concrete (RC)

442 targets with the impact surface size of $675 \mathrm{~mm} \times 675 \mathrm{~mm}$. The steel projectiles have an ogive nose of

443 caliber radius-head (CRH) 3.0, length of $152 \mathrm{~mm}$, diameter of $25.3 \mathrm{~mm}$, and mass of $0.428 \mathrm{~kg}$. In

444 order to save the computational cost, only a quarter of the RC target and projectile are modeled, as

445 shown in Fig. 11. The 3D solid element (Type-164 in LS-DYNA) is employed for the projectile and

446 concrete target, and the beam element for the reinforcement bar, respectively. In order to save

447 computational time and ensure computational precision at the same time, the local mesh refinement

448 is employed for concrete target. Based on the mesh sensitivity analyses in [8] and further 
450 impact location, which is enlarged to $4 \mathrm{~mm}$ after a distance beyond ten times of the projectile

451 diameter. The eroding surface-to-surface contact is employed to define the contact behavior

452 between the projectile and RC target without friction which has minor effect on the projectile

453 penetration process [38]. As discussed in Section 3.1, the element erosion technique with the

454 criteria based on $\bar{\varepsilon}_{p}$ and $\lambda_{t}$ is adopted for the modified K\&C model, i.e., the element will be 455 deleted immediately when $\bar{\varepsilon}_{p}$ or $\lambda_{t}$ is greater than critical values, which is achieved by 456 user-defined material model. Since there is no available element erosion criteria in the original 457 K\&C model, the maximum principal strain criterion is adopted using *MAT_ADD_EROSION in 458 LS-DYNA.

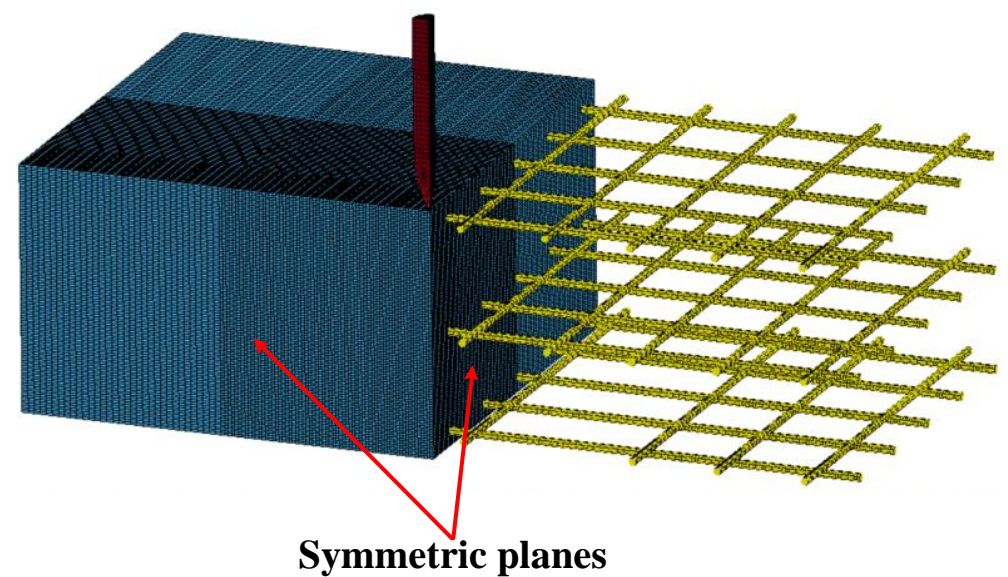

Fig. 11 FE model of the RC target and projectile

The steel projectile is modelled as rigid material as little erosion and deformation of projectile

462 have been observed. The reinforcement bar is modeled as the elastic, perfectly plastic material

463 (Mat_003 in LS-DYNA) with the elastic modulus of 210GPa and yield stress of 400MPa. For the

464 concrete material, the strength surfaces are defined by the parameters given in Eq. (10). The

465 damage related parameters, i.e., $\alpha, \alpha_{c}, \alpha_{d}$ and $\lambda_{m}$, adopt the suggested values shown in Fig. 6. 
466 Constant $n$ for the tensile damage is set as 100. Using the recommended relation between the static

467 fracture energy and the unconfined compressive strength of concrete given in [39] (i.e., $468 G_{f}=73 f_{c}^{0.18}, f_{c}$ in MPa unit), $G_{f}$ is found to be $140 \mathrm{~N} / \mathrm{m}$ for $f_{c}=41 \mathrm{MPa}$. Since the length of the

469 fracture zone is absent in this experiment, it is assumed to be the maximum diameter of aggregate

470 [17], i.e., 10mm. Consequently, els can be obtained using Eq. (18). Other constants are obtained

471 from the automatically generated method in the original $\mathrm{K} \& \mathrm{C}$ model. Table 1 presents all the 472 parameters of the modified K\&C model.

Table 1 Parameters of the modified K\&C model for 41MPa concrete

\begin{tabular}{l|c|c|c|c|c}
\hline \multicolumn{2}{l|}{ Strength surface } & \multicolumn{2}{|c|}{ Damage } & \multicolumn{2}{c}{ Others } \\
\hline$a_{0}$ & $1.73 \mathrm{e} 7 \mathrm{~Pa}$ & $b_{1}$ & 1.6 & $\rho$ & $2300 \mathrm{~kg} / \mathrm{m}^{3}$ \\
$a_{1}$ & 0.5698 & $b_{3}$ & 1.15 & $f_{\mathrm{c}}$ & $41 \mathrm{MPa}$ \\
$a_{2}$ & $6.14 \mathrm{e}-10 \mathrm{~Pa}^{-1}$ & $l_{\text {frac }}$ & $10 \mathrm{~mm}$ & $G$ & $12.8 \mathrm{GPa}$ \\
$a_{0 y}$ & $1.15 \mathrm{e} 7 \mathrm{~Pa}$ & $e l s$ & 2 & $T$ & $3.6 \mathrm{MPa}$ \\
$a_{1 y}$ & 0.8989 & $G_{f}$ & $140 \mathrm{~N} / \mathrm{m}$ & $\bar{\varepsilon}_{p}$ & 0.5 \\
$a_{2 y}$ & $1.67 \mathrm{e}-9 \mathrm{~Pa}^{-1}$ & $\lambda_{\mathrm{m}}$ & $8.7 \mathrm{e}-5$ & $\lambda_{t}$ & $8.7 \mathrm{e}-3$ \\
$a_{0 f}$ & 0 & $n$ & 100 & & \\
$a_{1 f}$ & 0.5698 & $\alpha$ & 3 & & \\
$a_{2 f}$ & $6.14 \mathrm{e}-10 \mathrm{~Pa}^{-1}$ & $\alpha_{c} ; \alpha_{d}$ & $0.29 ; 1.86$ & & \\
\hline
\end{tabular}


483 strain-rate discussed in Section 2.4, and the absence of a tensile failure criterion. The predicted

484 residual velocity agrees with the test data well, since it is mainly dominated by the compressive

485 behavior of concrete material.

486

487

488

489

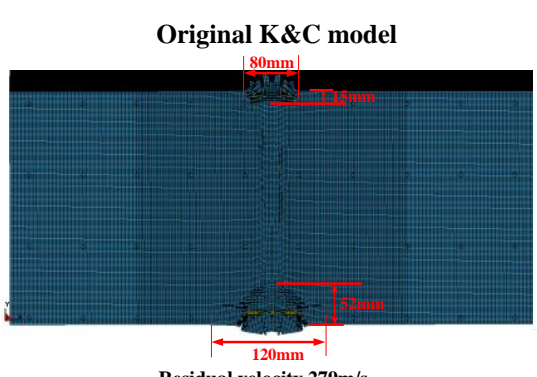

Residual velocity $279 \mathrm{~m} / \mathrm{s}$

(a)
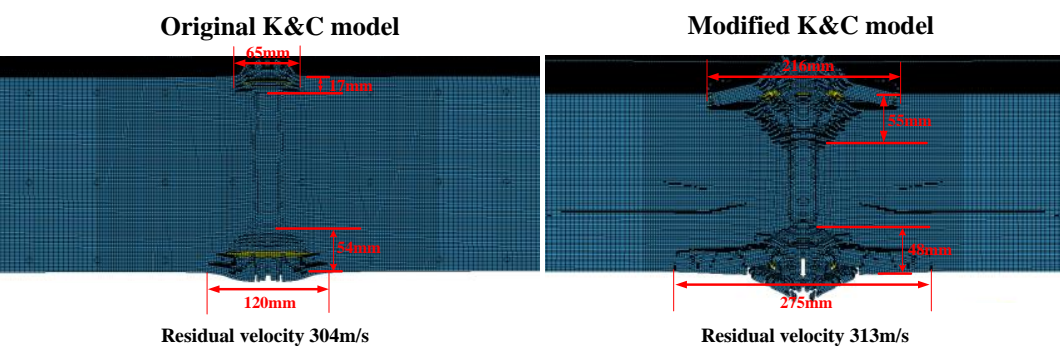

(b)
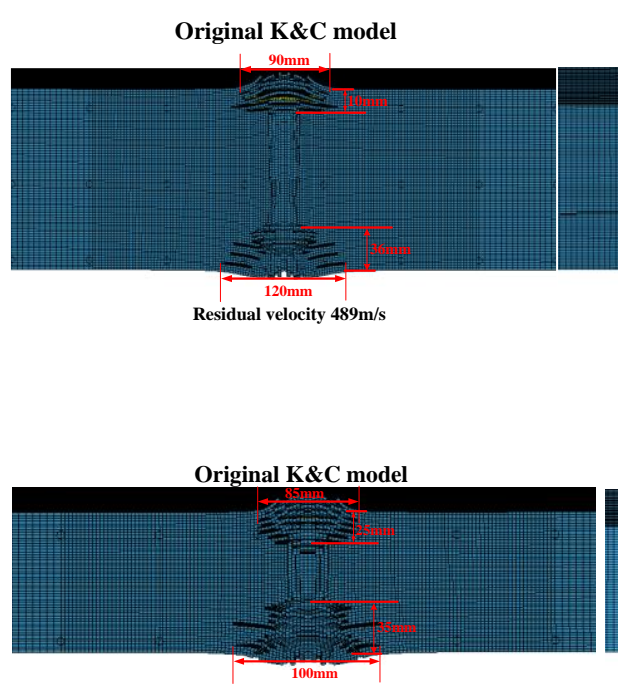

Residual velocity $368 \mathrm{~m} / \mathrm{s}$

Modified K\&C model

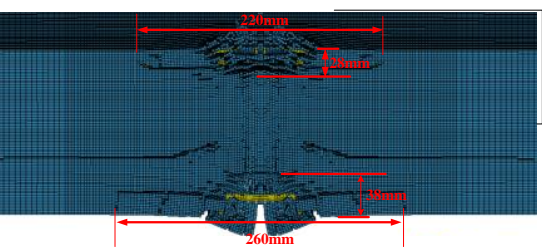

Residual velocity $507 \mathrm{~m} / \mathrm{s}$

(c)
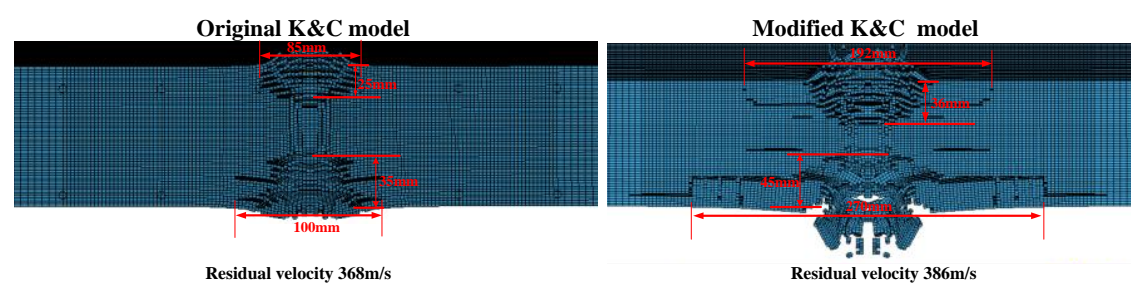

(d)

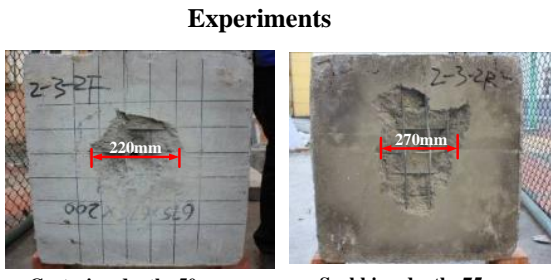

Cratering depth: 50mm

Sacbbing depth: $75 \mathrm{~mm}$

Residual velocity $323 \mathrm{~m} / \mathrm{s}$
Rear surface

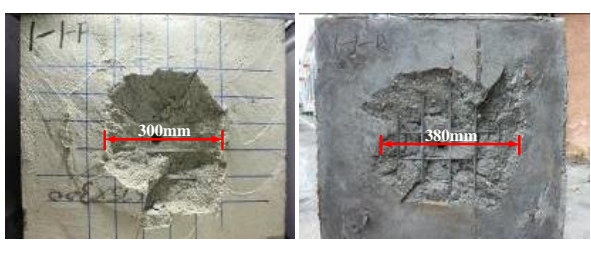

Sacbbing depth: $55 \mathrm{~mm}$

Residual velocity $272 \mathrm{~m} / \mathrm{s}$ 
projectile initial velocity $544 \mathrm{~m} / \mathrm{s}$; (c) shot No. 4-3: slab thickness $150 \mathrm{~mm}$, projectile initial velocity

$497643 \mathrm{~m} / \mathrm{s}$; (d) shot No. 5-3: slab thickness 100mm, projectile initial velocity 486m/s.

The predicted acceleration, velocity and displacement of the projectile and the

499 corresponding experimental data for shot No. 1-1 are shown in Fig. 13. The acceleration during

500 the perforation was recorded using the newly developed small-caliber accelerometer, which was

501 proved to be accurate and robust [2]. By integrating the acceleration-time curve, the velocity-time

502 and displacement-time of projectile can be obtained. It is found that both the original and modified

$503 \mathrm{~K} \& \mathrm{C}$ models have good agreements with the test data, as they are mainly governed by the

504 compressive behavior of concrete material.

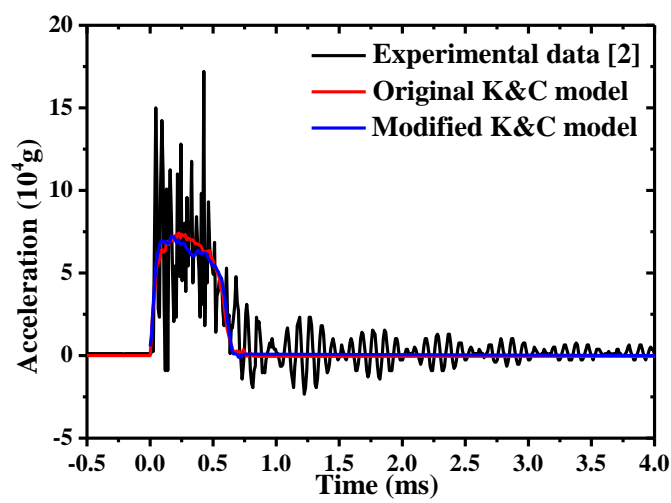

(a)

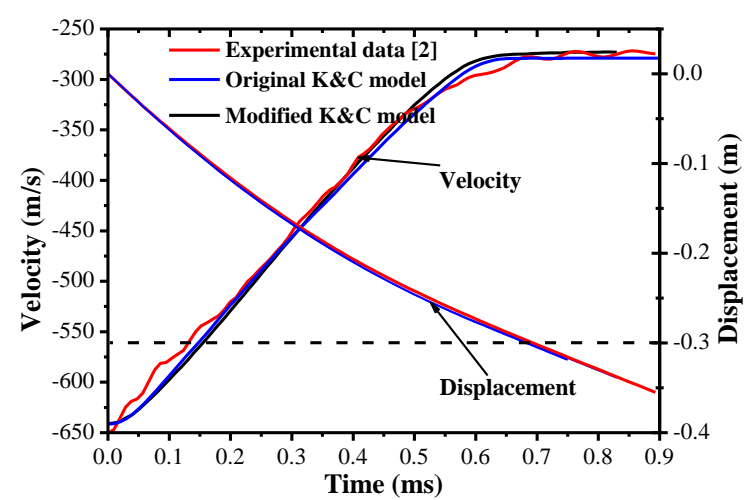

(b)

507 Fig. 13 Comparisons of simulation results with experimental data (a) acceleration; (b) velocity and displacement of projectile

512 of cratering and scabbing phenomena, is governed by six parameters in the modified model, i.e., 
514 from original and modified $\mathrm{K} \& \mathrm{C}$ models is mainly in the strain softening region, the influence of

515 parameter $b_{2}$, which governs the strain hardening, on the predicted cratering and scabbing sizes

516 should be small, and therefore, will not be discussed further. Sensitivity analyses of other five

517 parameters, i.e., $G_{f}, l_{f r a c}, T, n$ and $D I F t$, are carried out by varying one parameter by \pm 25 and \pm 50

518 percentages while other parameters are fixed. It should be noted that the purpose of parametric

519 studies is not to compare the simulation results with the corresponding experimental results, but to

520 investigate the influence of each individual parameter on cratering and scabbing phenomena. In

521 order to save computational time, the simulation from Section 3.2 with projectile initial velocity of

$522544 \mathrm{~m} / \mathrm{s}$ (shot No. 2-3) is chosen as a baseline.

\section{$523 \quad 4.1$ Influence of parameter $G_{f}$}

The influence of $G_{f}$ on cratering and scabbing sizes is shown in Fig.14, in which their

525 changing rates are defined as the relative changes of the quantities to their corresponding baseline

526 values. It is observed that the predicted cratering diameter, cratering depth, scabbing diameter and

527 scabbing depth decrease with the increase of $G_{f}$. Besides, the crack length decreases with the

528 increase of $G_{f}$ as a result of the increase of energy absorption capability of concrete material with

529 the increase of $G_{f}$.
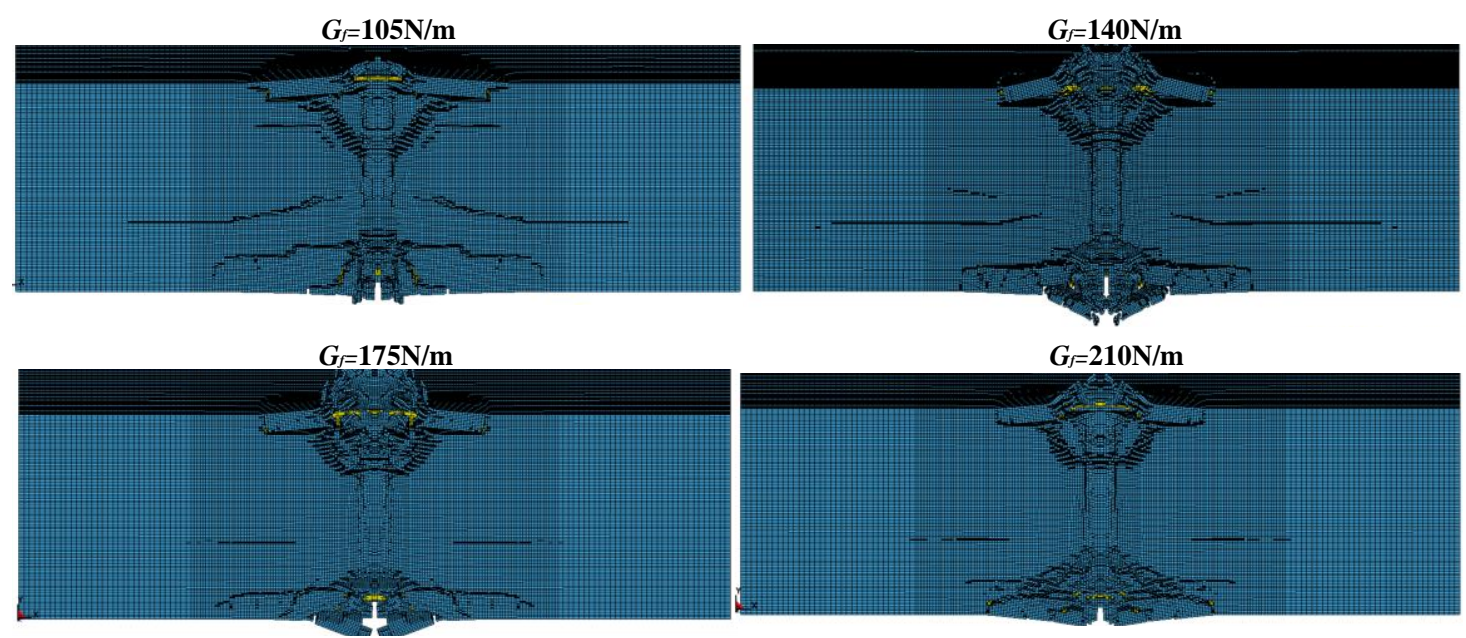

$G_{J}=\mathbf{2 1 0 N} / \mathrm{m}$

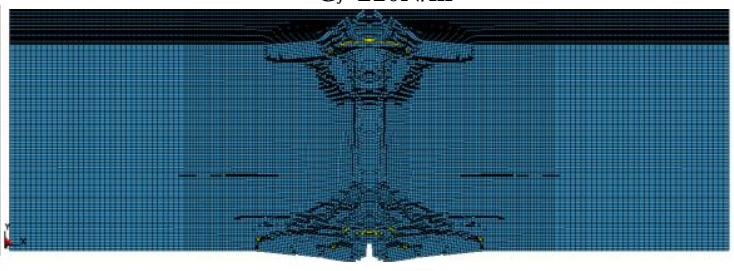


(a)

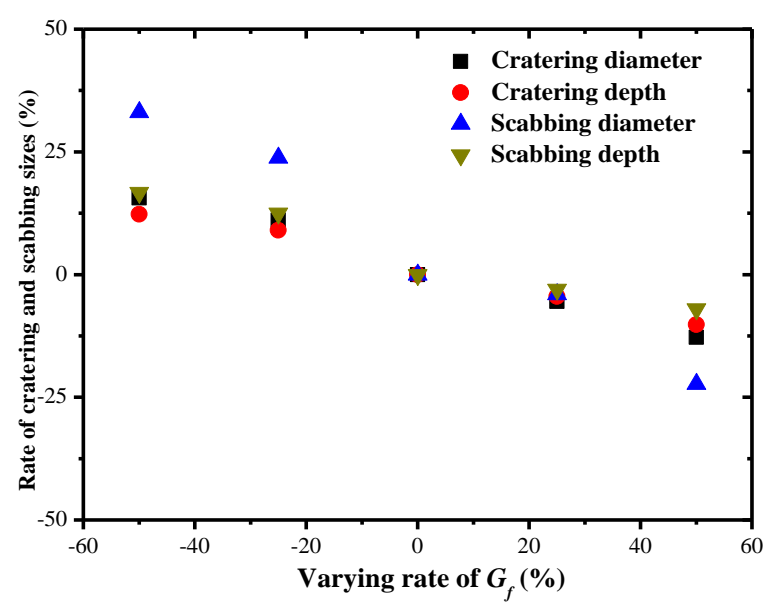

(b)

$534 \quad$ Fig.14 Effect of $G_{f}$ on cratering and scabbing, (a) simulation pictures; (b) predicted results

\section{$535 \quad 4.2$ Influence of parameter $l_{\text {frac }}$}

Figure 15 shows the influence of the parameter $l_{\text {frac }}$ on the cratering and scabbing sizes. In all

537 simulations, it is found that the failure modes are always similar for the values of $l_{\text {frac }}$ examined,

538 and thus, the simulation pictures are not presented. It can be found that the cratering and scabbing

539 sizes increase with the increase of $l_{\text {frac }}$. This is due to the fact that the increase of $l_{\text {frac }}$ leads to the

540 decrease of energy absorption capability in an element, i.e. each element of size $h c$ dissipates a

541 fracture energy of $\left(h \mathrm{c} / l_{\text {frac }}\right) G f$ since the fracture energy is assumed to be dissipated uniformly over

542 the length of the fracture zone $\left(l_{\text {frac }}\right)$.

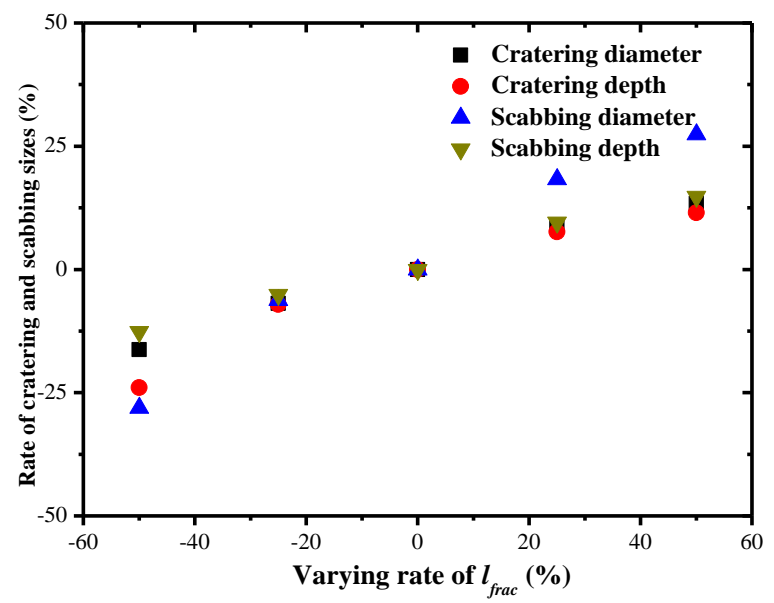


Fig.15 Effect of $l_{\text {frac }}$ on cratering and scabbing sizes

\section{$545 \quad 4.3$ Influence of parameter $T$}

The influence of $T$ on cratering and scabbing sizes is found to be evident, as shown in Fig.16.

547 Even though the fracture energy is hold constant, the predicted cratering and scabbing sizes

548 decrease with the increase of $T$ since the yield surface enlarges with the increase of $T$.

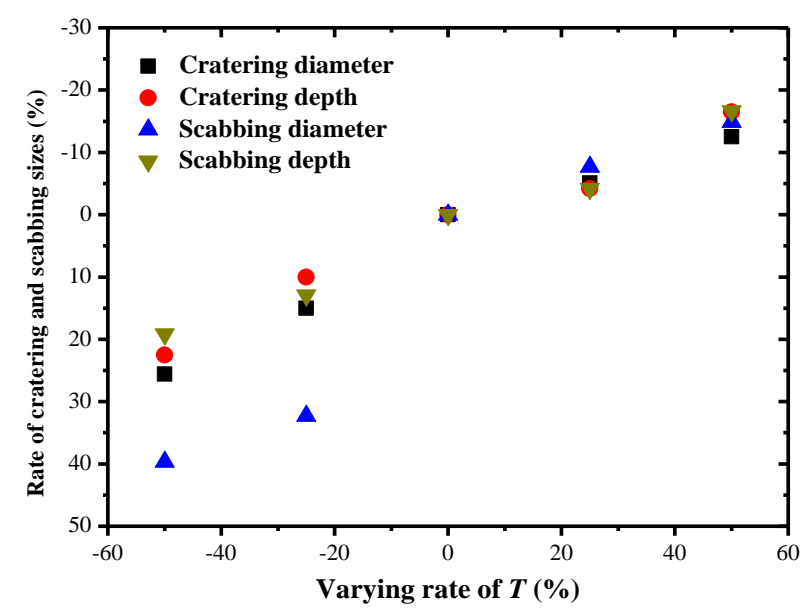

Fig.16 Effect of $T$ on cratering and scabbing sizes

\section{$551 \quad 4.4$ Influence of parameter $n$}

Figure 17 presents the influence of the parameter $n$ on the cratering and scabbing sizes. It is

553 observed that the cratering and scabbing sizes do not increase monotonously with the increase of $n$.

554 On one hand, the increase of $n$ results in the decrease of els according to Eq.(19). Meanwhile the

555 decrease of els could be linked to either the decrease of $G_{f}$ or the increase of $l_{f r a c}$ or T according to

556 Eq.(18). The decrease of $G_{f}$ or the increase of $l_{f r a c}$ (and thus the decrease of els) leads to the increase

557 of the cratering and scabbing sizes. On the other hand, the change of $\mathrm{T}$ will lead to the change of both els and

558 the yield surface, i.e. an increase of T will cause a decrease of els, making the cratering and scabbing sizes larger,

559 and meanwhile an increase of T will cause an enlargement of the yield surface, making the cratering and scabbing

560 sizes smaller. The overall changes of the predicted cratering and scabbing sizes reflect the competing of these two 
mechanisms.

However, the cratering and scabbing sizes, especially the scabbing size, are not very sensitive

563 to parameter $n$ when it is larger than 100. This is due to the fact that the dynamic tensile stress

564 approaches to zero when $n$ reaches a relative large value, beyond which the contribution of

565 dynamic stress-strain curve to the fracture energy is minor, as observed in Fig. 9. Therefore,

566 without invoking the complex calibration of tensile failure parameters, the proposed erosion

567 criterion with $\lambda_{t}>100 \lambda_{m}$ can be further used to describe other tensile-dominated failure

568 phenomena, such as the spallation of concrete slab subjected to blast loadings.

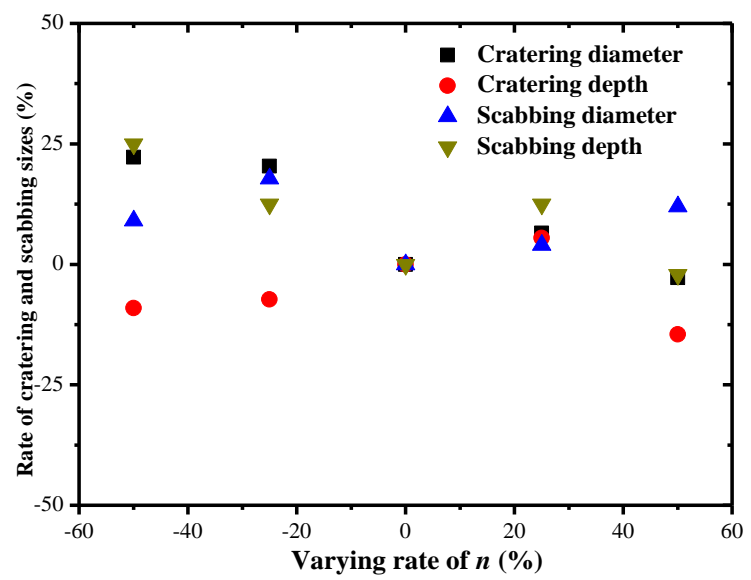

Fig. 17 Effect of $n$ on the cratering and scabbing sizes

\section{$571 \quad 4.5$ Influence of DIFt}

The influence of DIFt on cratering and scabbing phenomena is also found interesting. Fig.18

573 presents the different failure modes of simulation results using various DIFt, including the

574 suggested ones by Malvar and Crawford [29], by Xu and Wen [30] (Eq. (10)), CEB [27] and CEB

575 with a cutoff value of 10 . It is found that the predicted cratering and scabbing phenomena are very

576 similar using the suggested DIFt by Malvar and Crawford [29] and Xu and Wen [30], which are

577 actually close to each other, as shown in Fig.5. However, using the CEB recommended DIFt 
578 cannot reproduce the scabbing phenomenon well, since the CEB recommended DIFt greatly

579 underestimates experimental data, as shown in Fig.5. The same conclusion was presented in our

580 previous study based on a modified HJC model [8], which indicates that this conclusion is

581 independent of concrete material model.

DIFt suggested by Malvar and Crawford [29]

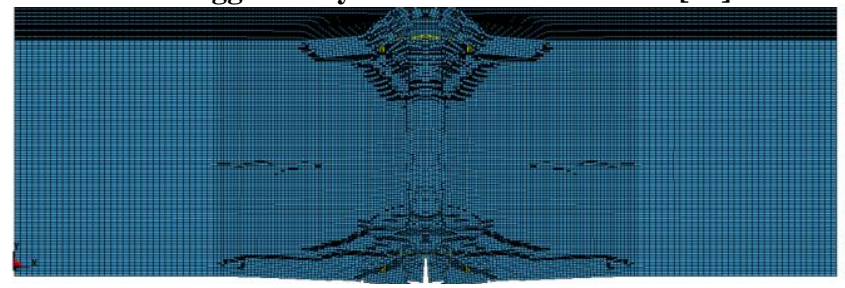

CEB recommended DIFt

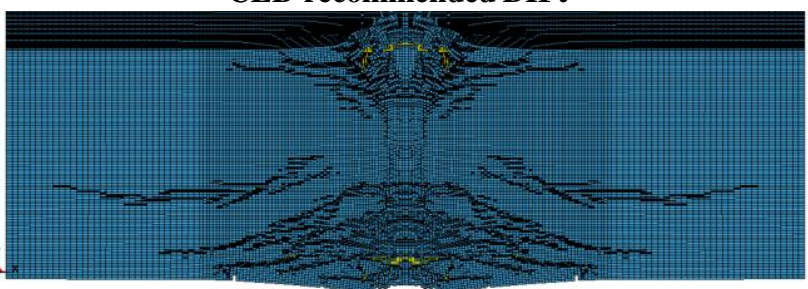

Present DIFt (Eq. (10), baseline)

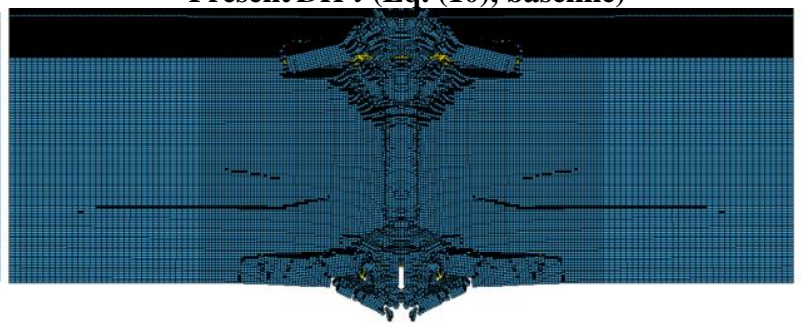

CEB recommended DIFt with cutoff value of 10

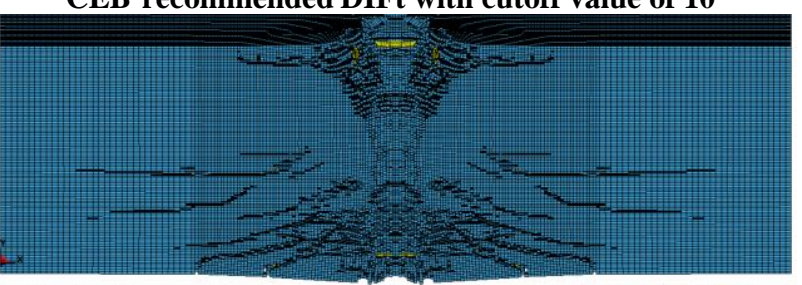

Fig.18 Effect of DIFt on cratering and scabbing

584 


\section{Conclusions}

587 The original $\mathrm{K} \& \mathrm{C}$ concrete model was modified and applied to simulate cratering and

588 scabbing phenomena in concrete slabs subjected to projectile impact. The main contributions and

589 findings are,

590 (1) Based on a large amount of triaxial compression data, the new strength surfaces

591 parameters for $\mathrm{K} \& \mathrm{C}$ model were proposed.

592

(2) A new relationship between the yield scale factor $\eta$ and the damage function $\lambda$ was

593 presented, which is more convenient and accurate than the original $\mathrm{K} \& \mathrm{C}$ model.

(3) Based on the experimental observation that the fracture strain is a constant and the

595 fracture energy increases with the increase of strain-rate for high strain-rate, a new tensile damage 596 accumulation formula relevant directly to the static fracture energy and fracture zone length was 597 established.

598 (4) A new tensile failure erosion criterion was proposed and validated by comparing with 599 projectile perforation test data and parametric study.

600 (5) Based on several sets of projectile perforation experiments into concrete slabs with 601 varying projectile impact velocity and concrete slab thickness, advantages of the modified K\&C 602 model for the simulations of cratering and scabbing phenomena were demonstrated.

603 (6) It was found that the scabbing size is sensitive to els and DIFt.

\section{Acknowledgements}

This study was supported by the National Natural Science Foundations of China (51210012, $60651522813,51238007,11272060)$. Helpful advices on K\&C model from Karagogian and Case Inc 607 through the cooperative project (51210012), and constructive comments from Dr S.R. Lan on the 
608 paper were gratefully acknowledged.

609 References

610 [1] Hanchak SJ, Forrestal MJ, Young ER, Ehrgott JQ. Perforation of concrete slabs with 48 MPa

611 (7 ksi) and $140 \mathrm{MPa}(20 \mathrm{ksi})$ unconfined compressive strengths. Int J Impact Eng 1992; 12(1):

$612 \quad 1-7$.

613 [2] Wu H, Fang Q, Peng Y, Gong ZM, Kong XZ. Hard projectile perforation on the monolithic

614 and segmented RC panels with a rear steel liner. Int J Impact Eng 2015; 76: 232-50.

615 [3] Wang ZL, Li YC, Shen RF, Wang JG. Numerical study on craters and penetration of concrete

616 slab by ogive-nose steel projectile. Comput Geotech 2007; 34(1): 1-9.

617 [4] Huang F, Wu H, Jin Q, Zhang Q. A numerical simulation on the perforation of reinforced 618 concrete targets. Int J Impact Eng 2005; 32(1): 173-87.

619 [5] Liu Y, Ma A, Huang F. Numerical simulations of oblique-angle penetration by deformable 620 projectiles into concrete targets. Int J Impact Eng 2009; 36(3): 438-46.

621 [6] Leppänen J. Concrete subjected to projectile and fragment impacts: Modelling of crack 622 softening and strain rate dependency in tension. Int J Impact Eng 2006; 32(11): 1828-41.

623 [7] Tu Z, Lu Y. Modifications of RHT material model for improved numerical simulation of 624 dynamic response of concrete. Int J Impact Eng 2010; 37(10): 1072-82.

625 [8] Kong XZ, Fang Q, Wu H, Peng Y. Numerical predictions of cratering and scabbing in 626 concrete slabs subjected to projectile impact using a modified version of HJC material model. Int 627 J Impact Eng 2016, 95: 61-71.

628 [9] Tu Z, Lu Y. Evaluation of typical concrete material models used in hydrocodes for high dynamic response simulations. Int J Impact Eng 2009; 36(1): 132-46. 
630 [10] Holmquist TJ, Johnson GR, Cook WH. A computational constitutive model for concrete 631 subjected to large strains, high strain rates, and high pressures. In: Proceedings of the 14th 632 International Symposium on Ballistics. Quebec: 1993. p. 591-600.

633 [11] Polanco-Loria M, Hopperstad OS, Børvik T, Berstad T. Numerical predictions of ballistic 634 limits for concrete slabs using a modified version of the HJC concrete model. Int J Impact Eng $6352008 ; 35(5): 290-303$.

636 [12] Islam MJ, Swaddiwudhipong S, Liu ZS. Penetration of concrete targets using a modified

637 Holmquist-Johnson-Cook material model. Int J Comp Meth 2012; 9(04): 1-19.

638 [13] Taylor LM, Chen EP, Kuszmaul JS. Microcrack-induced damage accumulation in brittle rock 639 under dynamic loading. J Comput Methods Appl Mech and Eng 1986; 55:301-20.

640 [14] AUTODYN Theory Manual (Revision 4.3). Century Dynamics, Inc.; 2003.

641 [15] Schuler H, Mayrhofer C, Thoma K. Spall experiments for the measurement of the tensile 642 strength and fracture energy of concrete at high strain rates. Int J Impact Eng 2006; 32: 1635-50.

643 [16] Weerheijm J, van Doormaal JCAM. Tensile failure of concrete at high loading rates: new test 644 data on strength and fracture energy from instrumented spalling tests. Int J Impact Eng 2007; 645 34(3): 609-26.

646 [17] Malvar LJ, Crawford JE, Wesevich JW, Simons D. A plasticity concrete material model for 647 DYNA3D. Int J Impact Eng 1997; 19(9): 847-73.

648 [18] Malvar LJ, Crawford JE, Morrill K B. K\&C concrete material model release III-automated 649 generation of material model input. Karagozian and Case Structural Engineers, Technical Report 650 TR-99-24.3, 2000.

651 [19] Xie HP, Dong YL, Li SP. Study of a constitutive model of elasto-plastic damage of concrete 
652 in axial compression test under different pressures. Journal of China Coal Society 1996; 21(3):

653 265-270. (in Chinese)

654 [20] Xiong YB. Research on constitutive parameters of concrete based on the Johnson-Holmquist 655 concrete model. Dissertation, Xi'an: Northwest Institute Nuclear of Technology, 2009. (in 656 Chinese)

657 [21] Ansari F, Li Qing-bin. High-strength concrete subjected to triaxial compression. ACI Mater J $658 \quad 1998,95(6): 747-755$.

659 [22] Yan DM, Lin G, Xu P. Dynamic strength and deformation of concrete in triaxial stress states. 660 Engineering Mechanics 2007: 24(3):58-64. (in Chinese)

661 [23] Wu JH, Yu HY, Li Q, Jiang YD. Experimental study on axial property for concrete with 662 constant surrounding pressure ratio. Journal of Experimental Mechanics 2007; 22(2):142-8. (in 663 Chinese)

664 [24] Hou ZG. Research on concrete strength under triaxial stresses. Dissertation, Hebei: Hebei 665 University of Technology, 2006. (in Chinese)

666 [25] Gebbeken N, Greulich S, Pietzsch A. Hugoniot properties for concrete determined by 667 full-scale detonation experiments and flyer-plate-impact tests. Int J Impact Eng 2006; 32: 2017-31. 668 [26] Lu YB, Li QM. About the dynamic uniaxial tensile strength of concrete-like materials. Int J 669 Impact Eng 2011; 38: 171-80.

670 [27] CEB-FIB Model Code 1990. Design Code. Lausanne, Switzerland: Thomas Telford; 1993.

671 [28] Zhou X, Hao H, Kuznetsov VA, Waschl J. Numerical calculation of concrete slab response to 672 blast loading. Transactions of Tianjin University, 2006, 12(Suppl.): 94-99.

673 [29] Malvar LJ, Crawford JE. Dynamic increase factors for concrete. In: Proceedings of the 28th 
674 DDESB seminar, Orlando, FL. ANSI Std.; 1998. p. 1-17.

675 [30] $\mathrm{Xu} \mathrm{H}$, Wen HM. Semi-empirical equations for the dynamic strength enhancement of 676 concrete-like materials. Int J Impact Eng 2013; 60: 76-81.

677 [31] Li QM, Meng H. About the dynamic strength enhancement of concrete-like materials in a split 678 Hopkinson pressure bar test. Int J Solids Struct 2003; 40(2): 343-60.

679 [32] Zhang M, Wu HJ, Li QM, Huang FL. Further investigation on the dynamic compressive 680 strength enhancement of concrete-like materials based on split Hopkinson pressure bar tests Part I: 681 experiments. Int J Impact Eng 2009; 36(12): 1327-34.

682 [33] Li QM, Lu YB, Meng H. Further investigation on the dynamic compressive strength 683 enhancement of concrete-like materials based on split Hopkinson pressure bar tests. Part II: 684 numerical simulations. Int J Impact Eng 2009; 36(12): 1335-45.

685 [34] Attard MM, Setunge S. Stress-strain relationship of confined and unconfined concrete. ACI 686 Mater J 1996; 93(5):432-42.

687 [35] Hallquist HO. LSDYNA user's manual. University of California, Lawrence Livermore 688 National Laboratory; 2003

689 [36] Xu K, Lu Y. Numerical simulation study of spallation in reinforced concrete plates subjected 690 to blast loading. Comput Struct 2006; 84: 431-8.

691 [37] Li J, Hao H. Numerical study of concrete spall damage to blast loads. Int J Impact Eng 2014; $692 \quad 68: 41-55$.

693 [38] Wu H, Fang Q, Zhang Y D, Gong Z M. Semi-theoretical analyses of the concrete plate 694 perforated by a rigid projectile. Acta Mech Sin 2012; 28(6): 1630-43.

695 [39] Federation Internationale du Beton. Fib model code for concrete structures 2010. Berlin: Ernst 

\& Sohn Publishing House; 2013. 